\title{
The effect of Ferulago angulata (Schelchet) Boiss on blood glucose levels and suppression of diabetes in rats
}

\author{
Rahil Parsamehr ${ }^{1}$, Somayeh Bohlouli ${ }^{2}$ \\ ${ }^{1}$ Department of Biology, College of Basic Science, Hamedan Branch, Islamic Azad University, Hamedan, Iran \\ ${ }^{2}$ Department of Veterinary Medicine, College of Agriculture, Kermanshah Branch, Islamic Azad University, \\ Kermanshah, Iran
}

Received December 8, 2016

Accepted June 13, 2019

\begin{abstract}
Diabetes mellitus is a metabolic disease characterized by elevated blood glucose levels. Medicinal plant Ferulago angulata has anti-oxidant properties. The aim of the present research was to evaluate the effect of a hydroalcoholic extract of $F$. angulata on the blood glucose level and liver enzyme activity in diabetic male rats. Forty-eight male rats were randomly divided into eight groups, including normal and diabetic groups. Diabetes was induced by a single intraperitoneal injection of streptozotocin at $40 \mathrm{mg} \cdot \mathrm{kg}^{-1}$ body weight. Rats were treated with an intraperitoneal injection of the extract for three weeks. At the end of the experimental period, fasting blood samples were collected, and blood glucose and liver enzyme activity were measured. This study demonstrated that serum glucose levels in diabetic groups treated with $F$. angulata were significantly lower than those in diabetic rats $(P<0.001)$. Alanine aminotransferase levels in diabetic rats treated with $F$. angulata were significantly decreased compared to diabetic rats $(P<0.001)$. Aspartate aminotransferase levels in diabetic rats treated with 200 and $400 \mathrm{mg} \cdot \mathrm{kg}^{-1}$ $F$. angulata were significantly decreased compared to diabetic rats $(P<0.001)$. No significant differences were observed in the serum levels of blood glucose and liver enzymes in the normal group treated with different doses of the extract. These results show that the hydroalcoholic extract of $F$. angulata might be effective in the treatment of diabetes and consequently alleviate the liver damage caused by streptozotocin-induced diabetes mellitus. This effect might be due to the presence of flavonoids and their antioxidant features.
\end{abstract}

Diabetic rat, herbal extract, liver enzymes, streptozotocin

Diabetes mellitus is a systemic disease of great significance. Compared to other diseases, diabetes is a disease of high prevalence. Type 2 diabetes mellitus is much more prevalent than type 1 diabetes. Diabetes-induced hyperglycaemia and hyperlipidaemia can cause many structural and metabolic disorders in different body organs including the liver ( $\mathrm{Li}$ et al. 2004). Liver is a key organ involved in glucose metabolism and energy homeostasis. A large amount of carbohydrates absorbed from the gastrointestinal tract undergoes hepatic processing and subsequent storage as glycogen or metabolism into amino acids or fatty acids. There is a very strong correlation between diabetes and liver disease (Friedman et al. 2003). The aminotransferases are the most frequently utilized and specific indicators of hepatocellular necrosis. Alanine aminotransferase (ALT) is primarily localized to the liver, but the aspartate aminotransferase (AST) is present in a wide variety of tissues like the heart, skeletal muscle, kidney, brain and liver (Li et al. 2004). Many studies have indicated that oxidative stress is also one of the major routes of pathophysiological condition during diabetes mellitus. Persistent hyperglycaemia causes increased production of free radicals, especially reactive oxygen species (ROS), in tissues from glucose auto-oxidation and protein glycosylation. Several reports have suggested that increased free radical-mediated oxidative stress is involved in diabetic complications (McGarry 2002). Use of medicinal plants in medicine is increasing because of their widespread use and curing various diseases

Address for correspondence: 
(Soto et al. 2003). Ferulago angulata, locally called "chavir", belongs to the Apiaceae family and is a natural and traditional plant in western parts of Iran (Khan Ahmadi et al. 2011). It also grows in other countries, including Turkey, Greece, Serbia and Macedonia (Baser 2002). The hydro-alcoholic extract of $F$. angulata contains phenolic compounds and has antioxidant and anti-diabetic effects. It is considered an important herb in Iran. Ferulago angulata extract is composed predominantly of ferulagone, $\beta$-hydroxy-13epi-manoyl oxide, $\alpha$-Pinene, 2,5-dimethoxy-p-cymene, p-Cymene, methyl carvacrol, transchrysanthenyl acetate, $\gamma$ - terpinene, $(Z)-\beta$-ocimene, $\alpha$-pinene, myrcene, terpinolene, 2,4,5-Trimethylbenzaldehyde and $\alpha$-phellandrene (Sodeifian et al. 2011). Phenolic compounds, owing to their antioxidant activity, are capable of inhibiting free radicals; thus, they can be effective in preventing many diseases like cancer, cardiovascular and nervous diseases (Hosseini et al. 2012). Ferulago angulata is a strong antioxidant and can be used instead of synthetic antioxidants in the food industry (Sadeghi et al. 2016a). The plant is an effective antioxidant that can stabilize sunflower oil and soybean oil during storage (Sadeghi et al. 2016b).

Administration of $F$. angulata extract has shown a positive effect on the immunological indices and immune system activity in rainbow trout (Oncorhynchus mykiss) fingerlings (Bohlouli and Sadeghi 2016). Ferulago angulata has been found to have aphrodisiac properties, and has been used as sedative, tonic, remedy of digestive pains and haemorrhoids, etc. Since a long time ago, Ferulago species have been good for ulcers, snake bites, spleen and headache (Zare Shahneh et al. 2013). This study was carried out to evaluate the effects of F. angulata (Schelcht) Boiss on blood glucose levels and liver enzymes of male rats.

\section{Materials and Methods}

Preparation of a hydro-alcoholic extract of $F$. angulata

Ferulago angulata plant used in this study was obtained from the Dallaho Mountains of Kermanshah in western Iran in late spring. The plant was identified by the herbarium of the Islamic Azad University, Kermanshah Branch. The fresh plant (stem, leaf and flower) was dried and powdered. Two hundred $g$ of powdered plant were kept in $500 \mathrm{ml}$ of $70 \%$ ethanol for $48 \mathrm{~h}$ at room temperature. Ferulago angulata powder and ethanol mix were stirred occasionally, and then alcohol and powder mix were finely filtered to obtain its extract. The obtained extract was distilled in vacuum to evaporate its alcohol completely. The soaked plant was extracted by the percolation method, removed from the percolator, and filtered by the Whatman filter paper grade $4(20-25 \mu \mathrm{m})$. It was dried under reduced pressure at $37{ }^{\circ} \mathrm{C}$ with a rotator evaporator (Bohlouli and Sadeghi 2016). The F. angulata extract is predominantly composed of ferulagone, $\alpha$-Pinene, 2,5 -dimethoxy-p-cymene, $\mathrm{p}$-Cymene, $\gamma$ - terpinene, (Z)- $\beta$-ocimene, $\alpha$-pinene, myrcene, and terpinolene.

Animals

Forty-eight male Wistar rats (230-250 g) were purchased from the Pasteur Institute (Tehran, Iran) and kept at a temperature of $22 \pm 2{ }^{\circ} \mathrm{C}$ and humidity of $55.0 \%$ under controlled environmental conditions, 12/12 h lightdark cycle with free access to water and food for two weeks before the start of the experiment so that they could adapt to the environment. The rats were fed standard pellets of rat diet and allowed to drink water ad libitum. The university ethics committee approved the animal experiments in this study.

Induction of experimental diabetes

Diabetes was induced using streptozotocin (STZ) (Sigma-Aldrich ${ }^{\circledR}$, St. Louis, MO, USA). After overnight fasting, diabetes was induced by a single intraperitoneal injection of a freshly prepared solution of STZ $\left(40 \mathrm{mg} \cdot \mathrm{kg}^{-1} \mathrm{~b} . \mathrm{w}\right)$ in a $0.1 \mathrm{M}$ citrate buffer $(\mathrm{pH} 4.5)$. After the third day of injection of STZ, the animals with fasting glycaemia higher than $200 \mathrm{mg} \cdot \mathrm{dl}^{-1}$ and with signs of polyuria and polydipsia were considered to be diabetic (Vasconcelos et al. 2011).

Treatment

In this study, 48 male Wistar rats $(230-250 \mathrm{~g})$ were randomly divided into 8 groups of 6 rats each:

Group 1: Normal control group treated with $0 / 5 \mathrm{ml}$ distilled water for three weeks

Groups 2, 3, and 4: Normal groups receiving intraperitoneal injections of the extract solved in distilled water at 100,200 and $400 \mathrm{mg} \cdot \mathrm{kg}^{-1}$ of body weight, respectively, for three weeks.

Group 5: Diabetic control group treated with distilled water for three weeks.

Groups 6, 7, and 8: Diabetic groups receiving intraperitoneal injections of the extract solved in distilled water at 100,200 and $400 \mathrm{mg} \cdot \mathrm{kg}^{-1}$ of body weight, respectively, for three weeks. 
Biochemical parameters

Twenty four hours after the last injection ( $21^{\text {st }}$ day), the animals were anaesthetized by diethyl ether (ether), after blood glucose was measured by using a glucometer (ACCU-CHEK-Roche Diagnostic GmbH, D-68298, Mannheim, Germany) (Sultana et al. 2014). Blood was taken from the heart and preserved at a temperature of $37^{\circ} \mathrm{C}$ for 30 min, and then centrifuged $\left(1000 \mathrm{~g}\right.$ ) for $15 \mathrm{~min}$. Serum was collected and preserved at $-20^{\circ} \mathrm{C}$ until measuring the blood glucose, ALT and AST levels. Measurement of ALT and AST activities in the serum was done using the end point colorimetric diagnostic kit (DIALAB, Australia) based on the formulation for the assay of AST and ALT as recommended by the international Federation of Clinical Chemistry (IFCC) (John et al. 2015).

\section{Statistical analysis}

The statistical analysis was carried out by one-way analysis of variance (ANOVA) and Tukey's test using SPSS software (Version 20). Statistical significance was considered at $P<0.05$.

\section{Results}

Our results showed that administration of the hydro-alcoholic extract of $F$. angulata to mature diabetic male rats resulted in a significant decrease in the blood glucose level compared to the diabetic control group $(P<0.001)$ (Fig. 1). No significant differences were observed in the serum levels of blood glucose in the non-diabetic group treated with different doses of the extract (Table 1)

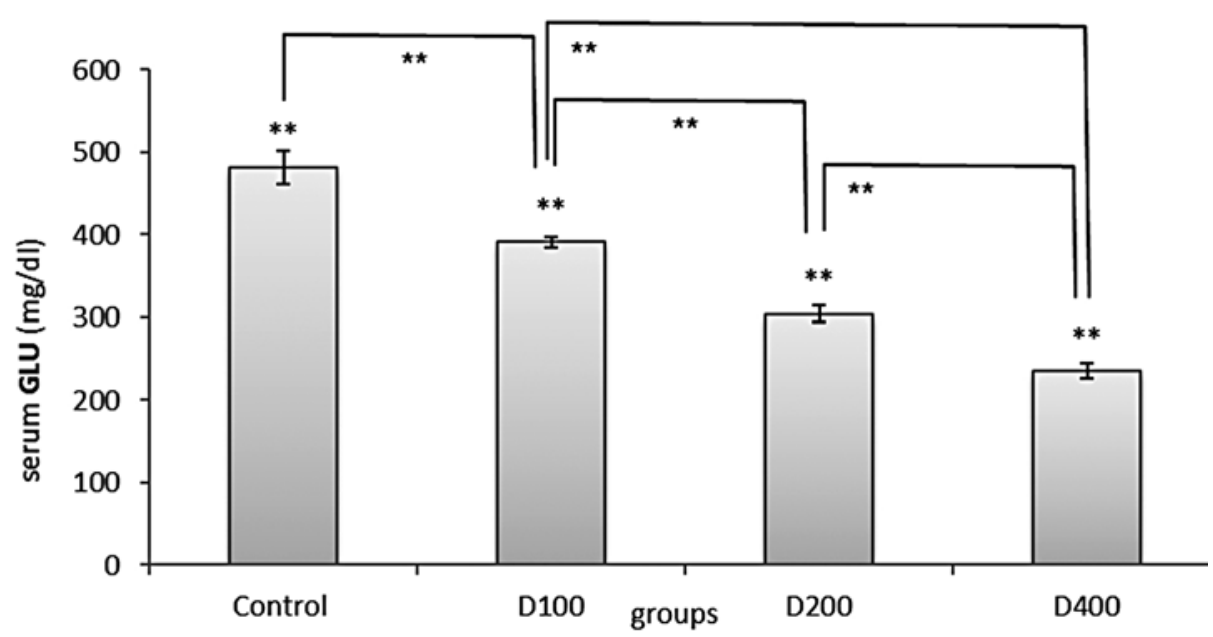

Fig. 1. The effect of different doses of the Ferulago angulata extract $\left(100,200,400 \mathrm{mg} \cdot \mathrm{kg}^{-1}\right)$ on serum glucose in diabetic male rats. Significant differences are shown by $* * P<0.001$ in comparison with the control group.

Table 1. The effect of the hydroalcoholic extract of Ferulago angulata on glucose, ALT and AST levels of normal rats.

\begin{tabular}{lccc}
\hline Groups & Glucose $\left(\mathrm{mg} \cdot \mathrm{dl}^{-1}\right)$ & ALT( U/1 $)$ & AST(U/1) \\
\hline Normal control & $107 \pm 2.012$ & $84.00 \pm 1.949$ & $136.33 \pm 3.615$ \\
Normal + extract $\left(100 \mathrm{mg} \cdot \mathrm{kg}^{-1}\right)$ & $108.33 \pm 1.801$ & $85.50 \pm 1.726$ & $136.50 \pm 1.87$ \\
Normal + extract $\left(200 \mathrm{mg} \cdot \mathrm{kg}^{-1}\right)$ & $108.33 \pm 1.726$ & $86.670 \pm 1.256$ & $138 \pm 1.41$ \\
Normal + extract $\left(400 \mathrm{mg} \cdot \mathrm{kg}^{-1}\right)$ & $109.33 \pm 1.115$ & $88.00 \pm .0966$ & $150.83 \pm 2.317$ \\
\hline
\end{tabular}

ALT - alanine aminotransferase, AST - aspartate aminotransferase. Data are expressed as mean \pm SD (standard deviation). No significant differences were observed in the serum levels of glucose and liver enzymes in the nondiabetic group treated with different doses of the extract. 
Our results showed that induction of diabetes in rats resulted in a significant increase in serum levels of ALT and AST enzymes compared to the control groups. Intraperitoneal injections of the hydro-alcoholic extract of $F$. angulata for 21 days reduced the levels of these enzymes in the diabetic rats compared to the diabetic control group $(P<0.001)$. However, no significant differences were observed in the serum levels of AST in the diabetic group treated with $100 \mathrm{mg} \cdot \mathrm{kg}^{-1}$ dose of the extract (Table 2).

Table 2. The effect of the hydroalcoholic extract of Ferulago angulata on ALT and AST in diabetic rats induced by streptozotocin (STZ).

\begin{tabular}{lcc}
\hline Groups & ALT(U/l) & AST(U/l) \\
\hline STZ control & $159.67 \pm 1.605$ & $205.50 \pm 1.839$ \\
STZ + extract $\left(100 \mathrm{mg} \cdot \mathrm{kg}^{-1}\right)$ & $131.50 \pm 1.821^{* *}$ & $193.67 \pm 1.801$ \\
STZ + extract $\left(200 \mathrm{mg} \cdot \mathrm{kg}^{-1}\right)$ & $121.17 \pm 2.639^{* *}$ & $175.50 \pm 1.765^{* *}$ \\
STZ + extract $\left(400 \mathrm{mg} \cdot \mathrm{kg}^{-1}\right)$ & $97.83 \pm 8.495^{* *}$ & $144.50 \pm 1.478^{* *}$ \\
\hline
\end{tabular}

ALT - alanine aminotransferase, AST - aspartate aminotransferase. Significant differences are shown by $* * P<$ 0.001 in comparison with the control group. Data are expressed as mean $\pm \mathrm{SD}$ (standard deviation).

Similarly, no significant differences were observed in the serum levels of liver enzymes in the non-diabetic group treated with different doses of the extract (Table 1).

\section{Discussion}

In this work, the effects of a hydro-alcoholic extract of $F$. angulata on the blood glucose level and liver enzyme activity were studied in diabetic male Wistar rats. Blood glucose levels significantly decreased in the diabetic rats treated with the extract. Four hundred $\mathrm{mg} \cdot \mathrm{kg}^{-1}$ dose of the extract showed the best effect in reducing blood glucose in diabetic rats.

In normal groups, there was a slight increase in blood glucose levels by increasing the dose of extract, showing no significant difference. The antioxidant activity of the plant extract is due to its active components, as a linear relationship between antioxidant activity of plant extracts and their phenolic content has been reported (Luximun-Ramma et al. 2002). On the other hand, phenolic compounds have antioxidant activity and protect the cells against oxidative reactions. Quercetin is an anti-diabetic ingredient of flavonoids found in red grapes, green tea and vegetables of the mustard family. Its intraperitoneal injection to diabetic rats resulted in a significant reduction in the plasma glucose level. Ferulago angulata contains flavonoids, and quercetin inhibits the absorption of glucose in the intestine; this is done specifically on the glucose transporter GLUT2. Consistently with our study, studies such as that of Rahimi et al. (2009) considered the presence of flavonoids and antioxidant properties, finding a Carthamus tinctorius petal extract (200 $\mathrm{mg} \cdot \mathrm{kg}^{-1}$ ) effective in hypoglycaemic activities (Rahimi et al. 2009). One study reported that the Otostegia persica extract can reduce the blood sugar level in diabetic rats. In general, this plant exerts its hypoglycaemic effects by reducing free radicals and through the presence of flavonoids such as quercetin (Hedayati et al. 2010). The anti-oxidant mechanism of quercetin is based on the removal of free radicals such as xanthine super oxide and xanthine oxidase (Mi and Zhang 2005). Treatments with quercetin in diabetic rats induced by STZ have reduced oxidative stress and increased insulin secretion (Khaki et al. 2009).

This herb contains flavonoids and phytosterol. Flavonoids have been found to have hypoglycaemic effects and to increase glucose uptake in normal rat muscle (Vessal et al. 2003) as well as to reduce blood glucose and to increase insulin levels in diabetic rats 
(Shirzad et al. 2010). The decrease in blood glucose observed in our study can be due to the effect of flavonoids in the F. angulata extract. Research shows that diseases caused by oxidative stress such as diabetes can be controlled and treated with antioxidants. Therefore, the antioxidant effects of the plant can be effective in reducing the oxidative stress and it has hypoglycaemic effect. Increasing the amount of flavonoids and other antioxidant compounds at higher concentrations of the extract can lead to a decrease in blood glucose levels in diabetic rats.

Liver is one of the organs that is damaged in diabetes, and ALT and AST are abundant in the liver. Liver cell damage is followed by an increased release of enzymes into the bloodstream. These enzymes are used to evaluate liver disorders. When increased, the above liver enzymes reflect liver damage. By increasing the dose of $F$. angulata extract in the diabetic groups, ALT and AST enzymes significantly decreased. The analysis of the effect of antioxidant compounds in improving the liver enzymes in diabetes showed that antioxidants such as quercetin, flavonoids, and phenolic compounds in the methanolic extract of Teucrium orientale are effective to protect the liver and reduce liver enzymes levels in diabetes (Dehghan et al. 2014). Another study demonstrated that the Launaea acanthodes extract, probably due to its flavonoids and antioxidant property, can prevent progressive increase in liver enzymes in diabetic male rats (Jalali et al. 2012). These findings are in line with the results of our study with regard to reducing liver enzymes in diabetic rats and can be attributed to the positive impact of $F$. angulata on reducing the activity of liver enzymes that were increased in diabetes. Diabetes disrupts metabolic actions and leads to increased oxidative stress. Due to oxidative stress and boosted production of free radicals, antioxidant systems are disabled and have an adverse impact on the liver. The increased activity of ALT and AST indicates liver damage. The ALT and AST levels in the normal groups increased by increasing the dose of extract, but this increase was not significant. Increased serum levels of ALT and AST in the normal groups treated with the extract can possibly be due to the increased activity in the liver to metabolize the extract, as a pharmaceutical substance, into the body of normal rats not treated with the extract. The findings of this study reflect the hypoglycaemic effects of $F$. angulata, at least in short-term. Probably antioxidants such as flavonoids in the extract reduce the free radicals and increase insulin secretion, thereby reducing blood glucose levels in diabetic rats. However, further studies are needed to evaluate all other possible mechanisms of the $F$. angulata extract involved in diabetes. In this study, the effect of the extract on liver damage due to diabetes was specifically pronounced, which might be related to the antioxidant compounds found in this plant. The antioxidant properties of the $F$. angulata extract depend on substances such as phenolic compounds, especially polyphenolic compounds. The F. angulata extract has a protective effect on the liver due to polyphenolic compounds such as flavonoids, which are the most important natural antioxidants. We can consider the Ferulago angulata extract as an anti-diabetic supplement for prevention of liver damage caused by oxidative stress in diabetes. However, further biochemical and pharmacological research is required to be conducted on the use of $F$. angulata.

\section{Conflict of interest}

There is no conflict of interest in this study.

\section{Acknowledgements}

This article was financially supported by the authors from the Hamedan Branch, Islamic Azad University, Hamedan, Iran and Kermanshah Branch, Islamic Azad University, Kermanshah, Iran.

\section{References}

Baser KHC 2002: Aromatic biodiversity among the flowering plant taxa of Turkey. Pure Appl. Chem 74: 527-545 Bohlouli S, Sadeghi E 2016: Growth performance and haematological and immunological indices of rainbow 
trout (Oncorhynchus mykiss) fingerlings supplemented with dietary Ferulago angulata (Schlecht) Boiss. Acta Vet Brno 85: 231-238

Dehghan G, Tahmasebpour N, Hosseinpour Feizi MA, Banan SMK, Sheikhzadeh F, Monirinasab H 2014: Effects of methanol extract of Teucrium orientale on the serum levels of glucose and lipids in diabetic rats. J Babol Univ Med Sci 16: 44-49

Friedman SE, Grendell JH, Mc Quaid Kenneth R 2003: Current diagnosis and treatment in gastroenterology. New York: Lang Medical Books/Mc Graw-Hill, pp. 664-679

Hedayati M, Pouraboli I, Pouraboli B 2010: Effect of methanolic extract of Otostegia persica on serum levels of glucose and lipids in type I diabetic male rats. Int $\mathrm{J}$ Endocrinol Metab 12: 435-442

Hosseini N, Akbari M, Ghafarzadegan R, Changizi Ashtiyani S, Shahmohammadi R 2012: Total phenol, antioxidant and antibacterial activity of the essential oil and extracts of Ferulago angulata ssp. angulata. J Med Plants 11: 80-89

Jalali M, Behnam Rasouli M, Tehranipour M, Ghayour N, Khayatzadeh J, Jannati H 2012: Study of the effects of hyperglycemia and Launaea acanthodes extract administration of liver function in rats. Physiol Pharmacol 15: $562-571$

John O, Pius Monday U, Nneka IW, Ogom OG, Uwaifiokun C, Benedict NL 2015: Effect of root and leaf extracts of tetracarpidiumconophorumon liver enzyme levels in alloxan induced diabetic rats. BJPR 5: 241-248

Khaki AA, Khaki A, Nouri M, Ahmadi Ashtiani HR, Rastegar H, Rezazadeh Sh 2009: Evaluation effects of quercetin on liver apoptosis in streptozotocin-induced diabetic rat. J Med Plants 8: 70-78

Khan Ahmadi M, Shahrezaei F, Alizadeh A 2011: Isolation and structural elucidation of two flavonoids from Ferulago angulata (Schlecht) Boiss. Asian J Research Chem 11: 1667-1670

Li WL, Zheng HC, Bukuru J, De Kimpe N 2004: Natural medicines used in the traditional Chinese medical system for therapy of diabetes mellitus. J Ethnopharmacol 92: 1-21

Luximun-Ramma A, Bahorun T, Soobrattee MA, Aruoma OI 2002: Antioxidant activities of phenolic, proanthocyanidin, and flavonoid components in extracts of Cassia fistula. J Agric Food Chem 50: 5042-5047

McGarry JD 2002: Banting lecture 2001: dysregulation of fatty acid metabolism in the etiology of type 2 diabetes. Diabetes 51: 7-18

Mi Y, Zhang C, 2005: Protective effect of quercetin on Aroclor 1254-induced oxidative damage in cultured chicken spermatogonial cells. J. of Toxicological Sci 88: 545-555

Rahimi P, Asgary S, Madani H, Mahzoni P 2009: Hypoglycemic effect of hydroalcoholic extract of Cathamus tinctorius petal on alloxan-induced diabetes rats. Knowlege \& Health J 4: 1-5

Sadeghi E, Mahtabani A, A Etminan A, Karami F 2016a: Stabilization of soybean oil during accelerated storage by essential oil of Ferulago angulata Boiss. Int J Food Sci Tech 53: 1199-1204

Sadeghi E, Karami F, Etminan A 2016b: The effect of Ferulago angulata (Schlecht) Boiss essential oil on stabilization of sunflower oil during accelerated storage. J Food Process Preserv DOI: 10.1111/jfpp.12745

Shirzad H, Shahrani M, Rafieian-Kopaei M 2010: Comparison of morphine and tramadol effects on phagocytic activity of mice peritoneal phagocytes in vivo. Int Immuno pharmacol 9: 968-970

Sodeifian G, Ansari K, Bamoniri A, Mirjalili BF 2011: Study of chemical composition of the essential oil of Ferulago angulata (Schelchet) boiss. From Iran using super critical fluid extraction and nano scale injection. Dig J Nanomater Bios 6: 161-168

Soto C, Recoba H, Barron C 2003: Silymarin increases antioxidant enzymes in alloxan-induced diabetes in rat pancreas. Comp Biochem Physiol Toxicol Pharmacol 136: 205-221

Sultana S, Khan MI, Rahman H, Nurunnabi ASM, Afroz RD 2014: Effects of ginger juice on blood glucose in alloxan induced diabetes mellitus in rats. J Dhaka Med Coll 23: 14-17

Vasconcelos CF, Maranhão HM, Batista TM, Carneiro EM, Ferreira F, Costa J, Soares LA, Sá MD, Souza TP, Wanderley AG 2011: Hypoglycaemic activity and molecular mechanisms of Caesalpinia ferrea Martius bark extract on streptozotocin-induced diabetes in Wistar rats. J Ethnopharmacol 137: 1533-1541

Vessal M, Hemmati M, Vasei M 2003: Antidiabetic effects of quercetin in streptozotocin-induced diabetic rats. Comp Biochem Physiol Toxicol Pharmacol 135: 357-364

Zare Shahneh F, Valiyari S, Azadmehr A, Hajiaghaee R, Bandehagh A, Baradaran B 2013: Cytotoxic activities of Ferulago angulata extract on human leukemia and lymphoma cells by induction of apoptosis. J Med Plants Res 7: 677-682 